\title{
An automatic micropipette fluid dispenser
}

\author{
JAMES ALLISON, DONALD M. BAILEY, BERT L. MIKESELL, and JOHNNIE WALTKE \\ Indiana University, Bloomington, Indiana
}

\begin{abstract}
An automatic device for repeated dispensation of a precisely controlled amount of fluid is described. The device employs a repeating micropipette powered by an electric motor geared to a rack-and-pinion drive. In our particular application, thirsty rats work for $0.2-\mathrm{ml}$ shots of water delivered to a metal spout connected to a drinkometer circuit. This arrangement permits the recording of both volumetric intake and the number of licks directed at the spout.
\end{abstract}

If the thirsty rat must work relatively hard for access to a water spout and is then allowed to make a controlled number of licks as its reward, it licks relatively efficiently, getting a relatively large amount of water per lick (Allison, Buxton, \& Moore, 1987; Buxton \& Allison, 1990). This finding has some importance for students of behavioral economics, foraging theory, and the methodology of reward. A question that soon comes to mind is whether or not rats make a similar adjustment in efficiency when each reward consists not of a controlled number of licks, but of a controlled volume of water. For example, if each reward consisted of a $0.2-\mathrm{ml}$ shot of water, would the rat take relatively few licks to ingest this water if it paid a relatively high behavioral price for each reward?

Research on this question is in progress. To get the research underway, we developed an inexpensive fluid dispenser that other investigators may find useful for their own purposes. In our application, the device delivers a controlled volume of water to a metal Licksit spout connected to a conventional drinkometer unit that senses licks at the spout. We know of no commercial system that combines these two features; typical systems either detect licks or dispense a controlled volume of fluid (Marwine \& Collier, 1979) by means of an infusion pump or a motorized dipper mechanism, and they cost appreciably more than our dispenser.

The heart of our device is a repeating micropipette. When its plunger is pushed home, the micropipette dispenses a specified volume of fluid. When the plunger is released, it returns to its initial position and reloads automatically from a reservoir. Although it was designed for manual operation, we found the device readily adaptable to automatic operation under computer control.

The top panel of Figure 1 shows the apparatus. The brass body of the micropipette is clamped in a white plastic bracket split horizontally for easy removal; it projects toward the lower right-hand corner of the photograph,

Correspondence should be addressed to James Allison, Department of Psychology, Indiana University, Bloomington, IN 47405. where the test chamber would be. The brass body ends with a threaded barrel tip; screwed to the tip is a plastic capillary that runs to the reservoir on the right, a Rubbermaid food container. The middle panel shows the driving mechanism in more detail. Positioned about $1 \mathrm{~cm}$ from the plunger is a padded strike plate attached to a bracket that rides horizontally on a tubular track. The bracket is moved back and forth by a rack-and-pinion drive. Power for the excursion and the return is furnished by a dc electric motor and a set of reduction gears that provide $5 \mathrm{lb}$ linear torque over a $2.5-\mathrm{cm}$ travel at a cycle rate of $1 \mathrm{cps}$. The bottom panel shows a detailed view of the plunger and the strike plate.

When the motor is operated, the strike plate moves forward and drives the plunger home. The Teflon tip of the plunger moves through the plastic capillary and dispenses one shot of fluid through the tubing shown at the right of the reservoir. A Microswitch limits the forward travel of the strike plate by causing the motor control circuit to reverse the direction of the dc motor. The strike plate then retracts until a rear Microswitch engages, stopping the motor and resetting the circuit for the next computeractivated dispensing cycle. As the strike plate retracts, the plunger returns automatically to its initial position, drawing the next shot of fluid from the reservoir.

The entire cycle, from computer activation through liquid dispensation and back to rest, takes approximately $1 \mathrm{sec}$. This speed depends on the rpm of the dc motor, the magnitude of the applied dc voltage, the gear ratios of the gear head, and the rack-and-pinion gears used. If it were necessary to control the rate of dispensation, a reversible ac synchronous motor, or a stepper motor plus the appropriate control circuitry, could be substituted for the components now in use.

In the present application, we deliver water through the tube to a metal spout that slants down into the test chamber. The tube is about $16 \mathrm{~cm}$ long, but it could be longer or shorter for other applications. The spout is a standard Licksit spout, with gravity feed, equipped with a valve that obstructs the flow of water. The water flows when the rat presses its tongue against the valve stem. A vertical shutter driven by an electric motor controls ac- 

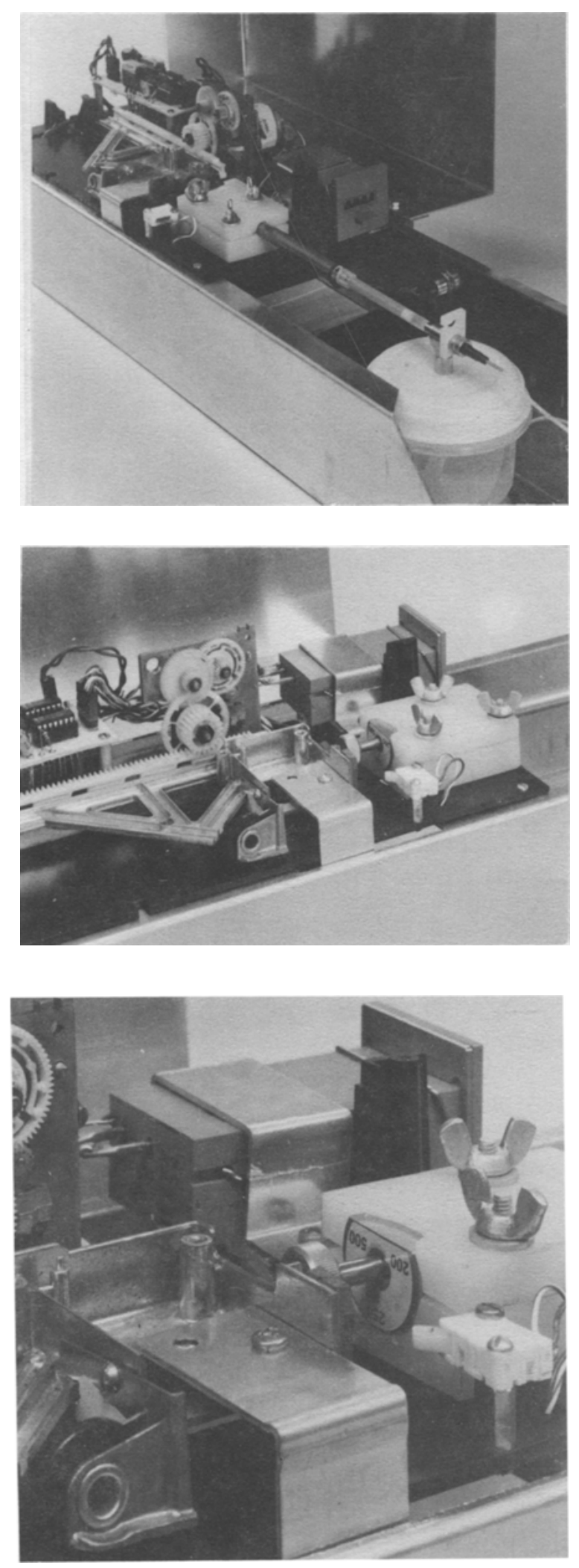

Figure 1. Automatic micropipette fuid dispenser. cess to the spout, which is connected in turn to a conventional drinkometer unit for the-detection of licks (Buxton \& Allison, 1990).

Our particular micropipette has three alternative settings obtained by rotating the plunger through three click stops: $0.50,0.25$, and $0.20 \mathrm{ml}$ per shot. Included with the package is a device for calibrating the dispenser. Also available from the same supplier are micropipettes with other sets of three alternative settings: $0.50,0.75$, and $1.00 \mathrm{ml} ; 2.0,2.5$, and $3.0 \mathrm{ml}$; and 4,5 , and $6 \mathrm{ml}$. The brand name is MICRO-RE/PETTOR, Series F, G, H, and K (Scientific Manufacturing Industries Inc., 1399 64th Street, Emeryville, CA 94608), and the list price of the unit is $\$ 225$.

The basic components of our drive system came from an RCA video disk player, SJT100/101/200/300. Used units can be obtained from various sources for $\$ 5$ to $\$ 10$. The key parts from the disk player were the dc motor, the rack-and-pinion drive, and the reduction gearing. The total cost, including miscellaneous electronic components for the control circuitry, was less than $\$ 300$ per dispenser. The 6-V, 500-mA dc motor is available from RCA as a replacement part (Motor Function Drive, Symbol No. B3, Stock No. 155879, Drawing No. 2816456-504). Radio Shack sells similar motors.

Two of these dispensers have been in service for several months. We find them rugged, reliable, and easy to calibrate. In a typical 1 -h experimental session, in which the rat works instrumentally for each 0.2 -ml delivery, the dispenser might make as many as 65 deliveries. We check for uniformity before and after each session by operating the pump 10 times and weighing the amount dispensed with an electronic scale accurate to $0.1 \mathrm{~g}$ ( $1 \mathrm{~g}$ of water $=1 \mathrm{ml}$ ). We find typically that the pump dispenses $2.0 \mathrm{~g}$ both before and after the session, so the mean amount per shot is close to $0.2 \mathrm{ml}$ and does not depend on the number of previous operations. Measurements of individual shots typically yield distributions with means of $0.2 \mathrm{~g}$ and variances equal to zero. We have operated each dispenser over 10,000 times, with no malfunction.

The manufacturer states that the Teflon tip of the plunger may drag excessively if the silicone lubrication inside the plastic capillary diminishes through usage. The cure is to replace the capillary, a cheap and simple procedure that we have not yet found necessary. The manufacturer also advises that tip wear may necessitate replacement of the tip after two or three thousand operations, another step we have not yet found necessary.

It is reasonable to suppose that service life will depend on the kind of fluid dispensed, and the care used in handling the micropipette. It may therefore be pertinent to emphasize that in our application we dispense a relatively innocuous fluid, room-temperature tap water, and that we operate the micropipette mechanically, not manually. Design details are available on request. 


\section{REFERENCES}

Allison, J., BuXton, A., \& Moore, K. E. (1987). Rats' responses to molar and local schedule constraints. Animal Learning \& Behavior, $15,360-367$.

Buxton, A., \& Allison, J. (1990). Efficiency and persistence of licking in rats. Physiology \& Behavior, 47, 239-247.
Marwine, A., \& Collier, G. (1979). The rat at the waterhole. Journal of Comparative \& Physiological Psychology, 93, 391-402.

(Manuscript received August 24, 1990; revision accepted for publication October $25,1990$. ) 